\title{
Assessing the effects of public participation processes from the point of view of participants: Significance, achievements, and challenges
}

\author{
by Catherine Martineau-Delisle ${ }^{1}$ and Solange $\mathrm{Nadeau}^{2}$
}

\begin{abstract}
Public participation practices are now common and recognized as a way of including a broader range of interests and social values in forest management. However, we know little about their real benefits. This article presents the results of a study aimed at developing a deeper understanding of the diverse impacts of public participation and, in particular, of forest-related deliberative forums (i.e. committee types of processes). The study is based on an analysis of data collected from 137 respondents-participants and coordinators-who have been involved in more than 120 forest-related public participation processes in the province of Quebec. The study examined the diversity of potential impacts of public participation processes, assessed the significance of the impacts, and evaluated the capacity of existing processes to achieve them. Overall, the study provides practical information to support the evaluation of public participation processes, a requirement that is increasingly imposed on forest practitioners and decision-makers.
\end{abstract}

Key words: forest governance, forestry, outputs/outcomes, impacts of citizen involvement/public participation processes, stakeholder consultation, advisory committees, evaluation, performance measurement, criteria and indicators, sustainable forest management, Canada, Quebec

\section{RÉSUMÉ}

Les processus de participation publique sont maintenant une pratique généralisée dans le secteur forestier; ils sont reconnus comme étant un moyen d'intégrer un éventail plus large d'intérêts et de valeurs sociales dans la gestion des forêts. Malgré cela, les connaissances demeurent fragmentaires sur les bénéfices réels de ces processus. L'article présente les résultats d'une étude visant à développer une compréhension approfondie des divers impacts reliés aux processus de participation publique et, en particulier, aux formes délibératives de mécanismes (ex. comités). Létude est basée sur une analyse de données amassées auprès de 137 répondants impliqués comme coordonnateurs et participants dans plus de 120 processus de participation publique liés à la gestion des forêts québécoises. L'objectif de l'étude était d'examiner la diversité des impacts potentiels des processus de participation publique, dévaluer leur importance, ainsi que de mesurer la capacité des processus à concrétiser ces impacts dans les faits. Globalement, l'étude offre des informations pratiques à même de supporter l'évaluation des processus de participation publique, une exigence à laquelle doivent de plus en plus répondre les praticiens et les preneurs de décision dans le secteur forestier.

Mots-clés : gouvernance des forêts, foresterie, retombées/résultats, impacts des processus de participation publique/ implication des citoyens, consultations des parties prenantes, comités de concertation, évaluation, mesure de performance, critères et indicateurs, gestion forestière durable, Canada, Québec

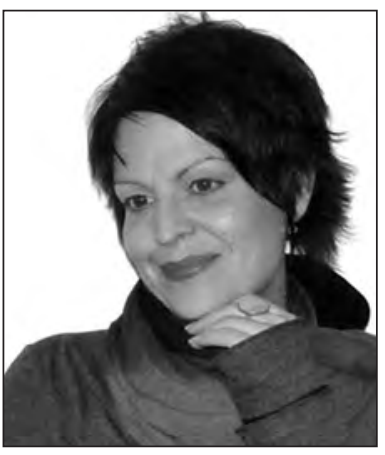

Catherine Martineau-Delisle

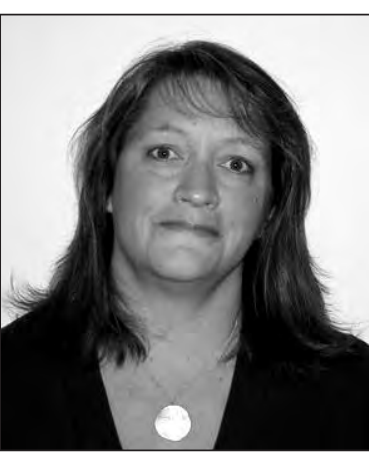

Solange Nadeau

\section{Introduction}

Interest in including a broader range of perspectives and social values in forest management has increased over the past two decades (McGurk et al. 2006). Flourishing of public participation in Canada confirms this trend: public hearings, citizen advisory committees, and other types of public participation mechanisms are numerous in the forest sector today (Robinson et al. 2001, Parkins et al. 2006, Martineau-Delisle [In prep.]). The increase in public participation is related to changes taking place in how public affairs are managed. A new form of governance is emerging that is characterized by a less centralized, more open style; a less formal, more collective approach; new processes; and involvement of a wider range of actors (Smouts 1998, Stoker 1998). With the advent of "sus-

\footnotetext{
${ }^{1}$ Sociologist, Laval University, 1520 Garnier, Québec, Québec G1S 2T5. E-mail: cmartineaud@gmail.com

${ }^{2}$ Senior Forest Sociologist, Natural Resources Canada, Canadian Forest Service - Atlantic Forestry Centre, 1350 Regent Street, P.O. Box 4000, Fredericton, New Brunswick E3B 5P7.
} 
tainable forest management (SFM)"-or "ecosystem management"- the forestry sector is experiencing a similar paradigm shift that has opened the door to initiatives that incorporate more public involvement (Cortner and Moote 1999, Howlett 2001, Stankey et al. 2005). For example, public participation is a requirement of the SFM criteria and indicators frameworks adopted by the federal and provincial governments as well as by the forestry-specific certification standards to which forest industries are subscribing (Canadian Standards Association [CSA 2002], Canadian Council of Forest Ministers [CCFM 2003], Forest Stewardship Council [FSC 2003]).

At the provincial level where forest management occurs, forest-related public participation processes are not only numerous but also varied. In Quebec, they mainly take the form of public hearings and committees. A review of these mechanisms over the last three decades shows major changes in the number of processes and in the way of involving the public (Martineau-Delisle [In prep.]). Mainly consisting of public hearings in the 1980 s, public participation processes started to increase and diversify in the 1990s, resulting in a figurative "explosion" by the turn of the century. The first decade of the new millennium has been distinguished by the quantity of processes in place, the growing decentralization of decision-making to regional or local entities, and, above all, by the growing number and dominance of more deliberative forms of public participation (e.g., committees). Many of these committees are related to industrial forest management planning on Crown land. Their growth follows the adoption of a new Forest Act in 2001, which explicitly requires that local interest groups be involved in the development phase of forest management plans (Lecomte et al. 2005). The introduction of forest certification standards has also encouraged the creation of forest-related committees (Cashore et al. 2005). The diversity of committees dealing with forest issues goes well beyond these "industrial" mechanisms. Although also aimed at producing a plan, others fall under the responsibility of municipal or regional organizations. Then, there are a number of committees that deal with more specific forestrelated issues such as integrated land management for a specific area, private forest management, road maintenance, or wildlife habitat protection.

Although public participation practices are now common and recognized as a way to include a broader range of interests and social values in forest management, knowledge of their real benefits is still limited (Selin et al. 2000, Buchy and Race 2001, Halvorsen 2003, Abelson et al. 2004, Abelson and Gauvin 2006). What exact gains or effects can be expected from public participation mechanisms? Taking this knowledge gap as a starting point, this article presents the results of a study aimed at developing a comprehensive understanding of the diverse impacts related to public participation, and, in particular, to forest-related deliberative forms of processes. The objectives of the study were to explore the diversity of potential impacts of public participation processes and to assess the significance of each when applied to committee types of mechanisms. The study also aimed to evaluate the capacity of committee types of processes to achieve the diverse impacts identified.

The study relies on data collected from 137 respondents involved as participants and coordinators in more than 120 of
Quebec's forest-related public participation processes (mainly committee types of processes). Data analysis revealed a broad range of effects that may result from public participation practices. It also enabled us to identify the types of impacts of most importance to forest actors as well as the types that may be most challenging to achieve.

The article begins with a brief presentation of the key research findings and knowledge gaps on the effects of public participation. Then, following an explanation of the methodology, the main results of the study are presented. The article concludes with a discussion of the findings, addressing their applicability to public participation practices and research as well as the parallels that exist between the study's results and other research findings in this domain. Overall, the article provides practical information to support the evaluation of public participation processes, a requirement that is increasingly imposed on forest managers/decision-makers.

\section{The Multidimensional Effects of Participatory Practices} The recent increase in public participation has prompted a renewed interest in research on public participation. Three dimensions of analysis predominate: the context, the process, and the outcomes (Dorcey and McDaniels 2001, Beckley et al. 2005, Abelson and Gauvin 2006). The context concerns the antecedents of a public participation process, i.e., factors that may have an influence on process and outcomes. For example, it includes dimensions such as the organizational environment and receptivity to participatory approaches, issue characteristics, history of past litigations or local conflicts, or decision-making context (OECD) 2001). The process dimension relates to the participatory mechanisms themselvestheir defining characteristics. Studies focussing on key public participation process traits often examine process criteria related to success. This paper focuses instead on outcomes, a dimension that has not been thoroughly explored until recently (Selin et al. 2000; Buchy and Race 2001; Smith Korfmacher 2001; Halvorsen 2003, 2006).

Among the studies on the impacts of public participation, some authors distinguish between deliberative forums (public spaces comprising public participation processes) and decision-making arenas (where decisions are made) and suggest that public participation processes are often more about deliberative window dressing than about a "real" change that would bring democracy into decision-making (Gaudin 1998, Lafaye 2001, Hamel 2003). According to this view, the fact that decision-making often happens in private arenas that are disconnected from the public forums where issues are debated would limit the impacts of public participation processes.

When looking specifically at the forest sector, some studies reach similar conclusions regarding the influence of public participation processes on decisions (Boon and Meilby 2000, Buchy and Race 2001, Dorcey and McDaniels 2001, McGurk et al. 2006). This research raises questions about the benefits of public participation processes; are they only limited to influence or power over decisions? $\mathrm{McCool}$ and Guthrie's (2001) study provides further insight by asserting that "narrow, product definitions of successful public participation are not widely shared by participants and factors other than interventions... may be central to their evaluation"(p. 
315), such as learning and trust building. In the context prevailing in Quebec, this perspective is even more relevant. Given that public participation processes tend to have limited formal decision-making power, thereby constraining their effective impacts (Dubé et al. 2004), these other types of impacts, which better reflect the real benefits of public participation processes, need to be explored.

Some studies describe the potential range of effects of public participation processes more exhaustively (Moore 1996, Guston 1999, Einsiedel et al. 2001, Konisky and Beierle 2001, Côté and Bouthillier 2002, Halvorsen 2003, Rowe and Frewer 2004, Abelson and Gauvin 2006). For example, public participation processes generate information exchange among participants, changes in operational planning, and trust. They also reduce conflicts. These effects go well beyond an impact on decisions; they include effects on the participants in the processes, and even on the way public participation itself is approached.

Building on the main types of impacts presented in the literature, an initial three-fold categorization of the effects of public participation emerges: effective, procedural, and reflexive impacts. Effective impact refers to the decisions made following participation, the concrete "products" or outputs of the process. This includes the production of a plan, the signing of an agreement, the formulation of a decision, or the introduction of a policy or a measure (Landre and Knuth 1993, Guston 1999, Boon and Meilby 2000). Procedural impact refers to the way public participation processes are delivered (Guston 1999, Einsiedel et al. 2001). This relates to the impact on the exercise itself (i.e., the adjustments made during the process) as well as on the lessons learned regarding the way to implement and conduct similar initiatives in the future. These are impacts on "general thinking" about the method of staging public participation. According to Guston (1999), this type of impact is more prevalent in new or exceptional approaches and can occur over time to facilitate an effective impact. Reflexive impact is linked to participants in the processes where participants learn important lessons despite being unsuccessful in changing policy (Guston 1999). Reflexive impact refers first to an increase in knowledge on an issue, on management approaches (e.g., ecosystem management), on environmental processes, or on procedural requirements (Landre and Knuth 1993, Guston 1999, McCool and Guthrie 2001). It can also refer to the individual competencies developed by participants, including the development of new perspectives (Landre and Knuth 1993). Involvement in a public participation process allows the participants to develop certain "skills" likely to contribute to their ability to intervene publicly in a more effective and confident manner (Lequin 2001, McCool and Guthrie 2001). Lastly, reflexive impact refers to the interactions and inter-relations that develop among the actors-the improvement in their capacity to interact in a public space. Often referred to as "relationshipbuilding", this includes an increase in trust or a better understanding of and greater respect for the situation of each player and their concerns or values (Landre and Knuth 1993, Johnson and Campbell 1999, McCool and Guthrie 2001). Overall, these three broad categories of impacts constitute a helpful starting point for the study of public participation mechanisms such as deliberative forums (e.g., advisory committees).

\section{The Gaps: Improving the Analysis of the Impacts of Participatory Practices}

Despite increased interest in the impacts of participatory mechanisms, numerous knowledge gaps remain that limit our capacity to assess and report on public participation outcomes. First, there is no widely accepted systematic approach for evaluating the impacts of public participation (Selin et al. 2000, Abelson and Gauvin 2006). A corollary to this is that the terminology used to describe the impacts of public participation mechanisms remains imprecise and inconsistent, with terms that are very diverse (e.g., objectives, benefits, outputs, outcomes, effects, impacts, and goals). Confusion also arises when assessing the characteristics of a mechanism that is treated as equivalent to assessing its impacts. This is problematic because the impacts of a mechanism refer to the ends of public participation (outcomes) and the characteristics refer to the means (inputs) conducive to achieving these ends (Tuler and Webler 1999).

When looking specifically at existing conceptual tools, very few of them go beyond a fragmentary-and often normative-representation of impacts. For example, empirical studies often focus their assessment on a specific impact of a single public participation process (e.g., knowledge acquired by participating in a committee; Monnet 2005). Many also follow a top-down approach, identifying impacts first and then assessing them afterwards (Selin et al. 2000). Furthermore, analyses of the impacts of public participation processes often do not include participants' perceptions even though recent studies demonstrate how the views of participants can enhance the assessment of participatory processes (Landre and Knuth 1993, Moore 1996, Duram and Brown 1999, Diduck and Sinclair 2002, Germain et al. 2001, Hunt and Haider 2001, McCool and Guthrie 2001). In summary, basic knowledge gaps still have to be filled.

Given these observations, the study aims to develop a more comprehensive understanding of the impacts of public participation. From a practical point of view, it provides a reference point for the evaluation of the impacts of participatory mechanisms (e.g., the types of outcomes and dimensions that may be evaluated and reported on). It also provides directions on where efforts can be made to ensure desired impacts occur (Beierle and Cayford 2002).

\section{Methods: Sample, Collection of Data, and Method of Analysis}

The study used a two-pronged approach to data collection (Landre and Knuth 1993, Lauber and Knuth 1999). First, semi-directed interviews were conducted with 24 people identified from lists of participants from both the committee and public hearing types of processes ${ }^{3}$. Interviewees were selected based on the representativeness of the interests at

\footnotetext{
${ }^{3}$ Three Quebec regions were selected for data collection: CapitaleNationale, Abitibi-Témiscamingue, and Laurentides. The interviewees come from public participation cases identified through the review conducted for the project "Public participation and sustainable forest management" (Laval University, Canadian Forest Service, and Sustainable Forest Management Network). For further details see Martineau-Delisle [In prep.].
} 
stake in Quebec's forest sector ${ }^{4}$ and their experience related to public participation ${ }^{5}$. The interview questions documented potential impacts of public participation processes in general and impacts that might be less obvious to respondents. Questions were pre-tested on 13 respondents.

A questionnaire with open-ended questions regarding the achievements or successes and the difficulties or challenges facing the committee-type of public participation processes followed; it was sent to coordinators of forest committees ${ }^{6}$ in Quebec who were known to have played diverse roles in relation to public participation processes. Representing committees from almost all of Quebec's administrative regions ${ }^{7}$, including urban, rural, and remote forest regions, 113 completed questionnaires were analyzed ${ }^{8}$. The committees analyzed were established between 1975 and 2006; the mandate of some was completed, and others were still active or in a transition period.

To address the first study objective-explore the diversity of potential impacts of public participation processes-data from interviews and questionnaires were analyzed using qualitative methods (Strauss and Corbin 1990, Miles and Huberman 1994, Moore 1996, Guston 1999, Tuler and Webler 1999, Webler and Tuler 2000). Each excerpt was coded according to the exact subject mentioned (detailed codes), and grouped into larger categories according to the similarities and differences existing between the themes andcodes identified 9 . Finally, the "grouped codes" were assembled to "reconstruct" the types of impacts to which they referred. This generated a reference framework composed of 10 potential impact types of public participation processes. More concretely, these notions can be conceived on a continuum where more abstract impact types are at one end and more concrete detailed codes, or indicators, are at the other.

For the second study objective-assess the significance of

\footnotetext{
${ }^{4} \mathrm{~A}$ typology of forest actors composed of 10 types was used to cover the range of interests involved in Quebec's forest sector: Governmental, Environmental, Regional and municipal, Individual, Community, Economic, Aboriginal, Wildlife, recreation and tourism, Professional and workers oriented, and Research and education. For further details, see Martineau-Delisle [In prep.].

${ }^{5}$ e.g., quantity of processes in which they participated, being public hearings or committees, and diversity of roles played: coordinator, participant, resource person.

"Only "committees" were analyzed because the literature posits a distinction between traditional and "deliberative" mechanisms (e.g., public hearing / committee) and proposes separate benefits (as confirmed in the interviews and in responses to the questionnaire sent).

${ }^{7}$ The two regions where there were no committees are Montreal and Laval.

${ }^{8}$ Of the 351 committees identified, those whose status was confirmed at the time of the study were retained. From the 184 questionnaires sent, 126 were returned (response rate: $68 \%$ ). Some were excluded because the case to which they applied did not meet criteria or because there was no response to the questions concerned (61\%).

${ }^{9}$ Detailed codes were labelled "indicators" and grouped codes labelled "indicator categories". Thus, each type of impact is composed of one or many grouped codes ("indicator categories") composed themselves of one or many detailed codes ("indicators"). For the complete version of the framework, see Martineau-Delisle [In prep.].
}

the impacts identified and evaluate the capacity of existing processes (committee types in particular) to achieve themwe adopted a quantitative approach using descriptive statistical analysis of data (Boon and Meilby 2000; Halvorsen 2001, 2003; Irvin and Stansbury 2004; McGurk et al. 2006). Information collected from the questionnaire was first compiled and coded according to the reference framework's dimensions. Confined to an analysis of the relative significance of each impact, the results present the percentage (\%) of respondents mentioning one or more of the 10 impact types identified. The focus was on the presence of one or more comments related to a specific impact or dimension. Information collected was then coded according to the positive or negative evaluation made by the respondents regarding the capacity of the mechanisms to concretely achieve the identified impacts. The impact components (detailed codes or indicators) that were mentioned by at least $10 \%$ of the respondents were isolated and then translated to a scale out of $100 \%$ to determine the negative or positive evaluation for each.

\section{The Impacts of Public Participation: Diversity, Signif- icance, and Gaps}

This section illustrates the diverse impacts that emerged from respondents' comments, the significance attributed to each impact, and the assessment of how well processes are doing in achieving them.

\section{Diversity of public participation process impacts as defined by those involved}

Ten impact types emerged from respondents' comments. Results were organized into five groups based on similarity (Table 1). These represent intermediate groupings between the three general categories of impacts outlined at the outset (effective, procedural, and reflexive) and the detailed types of impacts identified from respondents' comments.

One of the five groupings concerned the effects of public participation processes on decisions and actions and the involvement of a variety of participants. Here, respondents identified three specific types of impacts. Public participation processes were conceived as forums for exercising direct power and influence on management decisions (T1). Comments relating to this type of impact were on a continuum ranging from simple influence to real decision-making power, and even to legal authority. A second specific impact conceived public participation processes to be favouring concrete outcomes and greater effectiveness of the management process (T2). They were seen to play a tangible role in improving forest management (e.g., financial benefits related to the development of public lands, drafting of a plan). Finally, the last specific impact felt public participation opened management processes up to a wider range of interests and values beyond those actors that are traditionally involved (T3). For example, respondents highlighted the benefits stemming from the number of participants and from the wide range of groups involved (representation of various interests and sectors, of underrepresented participants, or of specialists from diverse fields).

A second grouping concerned the effects of public participation processes on the relevance and progressive adjustment of participatory practice. Here respondents identified one specific type of impact: the contribution of public partic- 
T'able 1. The impacts of public participation in forest management: five groupings and ten types (T)
Effective
A) An effect on decisions and actions, and on the involvement of a diversity of participants
T1: Direct power and influence on management decisions resulting from participation process
T2: Concrete outcomes and greater effectiveness of the management process
T3: Openness of forest management process to a wider range of participants than the traditional actors involved

Procedural B) Relevance and progressive adjustment of public participation practice

T4: Evolution of participatory practices towards approaches more suitable to local contexts and participants

Reflexive Cognitive C) Information and participant learning
T5: Acquisition and exchange of information and knowledge by participants
T6: Enhancement of participants' skills

Affective D) Mobilization of participants

T7: Expression of participants' motivation/commitment, and enhancement of their capacity to contribute to the management process

E) Relationships and interactions among participants

T8: Changes in attitudes and behaviours with regards to the self and to the others

T9: Communication among participants

T10: Development of a collective capacity for collaboration and relationships among participants

ipation towards the evolution of participatory practices more suitable to local contexts and participants (T4). Participatory processes were seen as being conducive to adaptive management and the inclusion of local traits and people in the design and implementation of public participation processes (e.g., continuous improvement or making structures more appropriate to their operational context).

A third grouping concerned the effects of public participation processes on information and participant learning. Respondents identified two specific types of impacts. Firstly, public participation was seen to fuel the acquisition and exchange of information and knowledge (T5). It thus permits an upgrading and passing on of information and knowledge regarding forest and forest management such as richer information and knowledge about relevant, well-documented subjects, information adapted to the participants, but also scientific, "expert", independent, and cutting-edge information (e.g., information that may be shared by officials in the course of roundtable meetings). Public participation processes also facilitate access, circulation, and pooling of information in a broader sense: sharing information among participants, integration of individual knowledge, as well as a broader diffusion of this information (outside public participation processes). Secondly, the processes are said to contribute to the development of participants' skills (T6): "ways of being" (individual qualities such as self-assurance), relational skills (ability to approach others), as well as know-how skills (e.g., experience in forest management). Some claimed that their participation even caused them to refine their approach when taking part in a public participation process (e.g., revise their intervention mode, create new alliances).

In the fourth grouping, the effects of public participation processes concerned the mobilization of participants. Respondents identified one specific type of impact: the perception that public participation processes allowed the expression of participants' motivation and commitment towards forest management (T7). Respondents' mentioned that it allowed them not only to express their interest in participating, but also to make an active and meaningful contribution to the management process. Respondents mentioned various benefits: from a growing interest in the subjects addressed to mobilization of strengths by the work of volunteers.

The fifth and final grouping concerned the effects of public participation processes on relationships and interactions among participants. Respondents identified three specific types of impacts. Public participation processes were seen to impact attitudes and behaviours (T8): toward oneself, others, and in general (e.g., increasing trust, credibility, and notoriety). These mechanisms were seen to help change people's mind-sets and the way they interacted with each other (i.e., individuals learn to respect others and adopt appropriate expression mode for making contact), openness and way of thinking (influence on the positions of others, and enrichment and stabilization of one's own positions). A second specific impact conceived public participation processes to enable communication among participants (T9). Respondents mentioned that it opened up a dialogue where people could listen to each other and have meaningful conversations. It also encouraged deliberation, whether in terms of fairness in floor time or freedom of expression (e.g., expression of diverging positions). Finally, the last specific impact conceived public participation processes to develop "collective" capacity among participants (T10). They present a way to create closer relations (knowledge and understanding of others) and to broaden networks. Public participation is also viewed as fostering collaboration and agreement among participants. Thus, it allows for compromise and the development of cooperation, team work, and group dynamics (e.g., cohesion). For example, people get in the habit of supporting each other and working together on projects; the participation of organizations with priorities, which at first glance seem incompatible, makes it possible to arrive at shared actions for the benefit of all. Finally, public participation processes are said to address disputes and conflicts, reconcile differences, and to identify points of consensus. 
Significant impacts and gaps according to participants' vision This section discusses how important each of the ten types of potential impact is to respondents. Table 2 presents the proportion of individuals $(n=113)$ that mentioned the ten types of impacts and the components of each type. Respondents assessment-negative or positive-about how well committee types of mechanisms achieved the 10 types of impact is analyzed (for components of impacts mentioned by more than $10 \%$ of respondents).

At the level of the five groupings, the grouping that concerned the impacts of public participation processes on decisions and actions and on the involvement of a diversity of participants predominated, being referred to by $82.3 \%$ of respondents. This was followed by the effects of public participation processes on the relationships and interactions among participants group (80.5\%), the mobilization of participants group (51.3\%), the information and education group (27.4\%), and the grouping regarding the progressive adjustment of participation methods (7.1\%).

At the level of individual impact types, collective capacity (T10) took first rank, with about two-thirds of respondents (65\%) mentioning at least one impact of this type. Regarding the components that comprised the impact type, many respondents felt that committees contributed to "knowledge and understanding" of the needs, problems, and values of other groups (77\%). They also spoke of important achievements in terms of "cooperation, group dynamics, and team work" (69\%): e.g., learning to work as a team, creating a group dynamic, developing collaboration and mutual support on shared issues and more solid agreement or quality relationships with others. Nonetheless, certain major challenges remained. The existing tension between collective and individual or corporate interests was noted (58\%). As a result, many raised problems associated with the achievement of consensus while respecting the interests of each party (which is even more complex with the presence of diverging expectations and the incompatibilities thus generated; 73\%).

Expression of participants' motivation and commitment, as well as enhancement of their capacity to contribute to the management process (T7), was the second most important impact according to opinions expressed (51\%). Regarding components, although some respondents noticed that committees generated growing interest among members, sustaining this interest does not seem to be a given (81\%), because of similar initiatives in the same region and of different levels of concern about the subjects raised, for example. Another important issue concerns what participation requires and the unequal resources at the disposal of the member organizations $(78 \%)$. The lack of time available to meet regularly is another problem mentioned (76\%).

Many respondents commented on the concrete outcomes and effectiveness of the management process (T2) resulting from mechanisms such as committees, which rank third in terms of importance among the ten types of impacts (49\%). The focus was on concrete impacts (accomplishments or actions resulting from committees' work). At the level of components, most discussed these tangible outcomes as achievements (88\%) in terms of improvement of infrastructures, production of management plans, development of tools, and economic benefit, for example. However, the operational framework is mentioned as a particular challenge (65\%). The respondents pointed out difficulties related to lack of funding or time as detrimental to committee effectiveness and the capacity to produce results.

Power and influence (T1) ranked fourth (36\%) among the 10 types of impacts. While respondents felt that committees have an increased influence on decisions (63\%), the great majority saw their decision-making power and capacity for action as challenges rather than achievements (73\%). Respondents spoke of difficulties related to lack of decision-making power and the limited capacity of committees to be proactive and to act autonomously (due to the lack of resources or necessary authority).

Ranking fifth among impacts, changes in attitude and behaviours (T8) were mentioned by $35 \%$ of respondents, whose assessment was mixed. Although some noted achievements in relation to improvement of trust among the actors (53\%), the mistrust of some, or feelings from past conflicts, pose a major challenge (47\%). Other difficulties relate to maintaining a positive outlook, an openness to the proposals of the various participants, or a constructive attitude (emphasis on solutions, not problems; 52\%). However, the activities of committees have contributed to increasing openness and to changing people's mind-set and way of thinking (48\%). Mentioned frequently as well are respect and mode of expression, albeit as being problematic (75\%). Certain key challenges persist in that regard: maintaining a constructive atmosphere in meetings, but also ensuring that each member or opinion is respected during interventions.

Almost all comments related to information and participant learning refer to the acquisition and exchange of information and knowledge (27\%), which ranks sixth among impacts (T5). At the level of components, the committees are seen as enriching knowledge in various areas such as forestry, forests, and management process (77\%). At the same time, a majority of respondents expressed concerns regarding the appropriateness and suitability of the information transmitted to participants (88\%). Formulated often as a lack/difference in levels of knowledge among the members, this aspect remains sensitive given the technical and scientific complexity of the issues discussed.

Impacts related to communication (T9) - mentioned by $23 \%$ of respondents (ranked seventh) - chiefly concerned the quality of discussion, which was regarded as a major achievement $(88 \%)$. Even though holding a marginal place in their comments, the pitfalls involved in allowing the greatest number of individuals to express themselves, but also in ensuring the capacity of the discussions to bring forth concerns and lead to solutions for all-and not always from the same people (i.e., seeking out the opinions of the less active participants)-are noted.

Respondents made few references to openness of the management process to other participants (T3), which ranked eighth (21\%). One component was about committees contributing to the integration of a good diversity of participants and interest sectors (67\%). However, difficulties related to the capacity to clearly identify all the participants and to contact certain groups among them, are highlighted. Although mentioned by less than $10 \%$, the respondents were also concerned about the skills and profile of the members: their relevance (e.g., connection to the mandate's objectives, affiliation with the territory), and their level of training or diversity of special- 
Grouped

impact types

1) Effect on decisions $\quad 82 \quad \mathrm{~T} 1$ : Direct power and and actions, and on the involvement of a diversity of participants influence on management decisions resulting from public participation process

T2: Concrete outcomes and greater effectiveness of the management process

T3: Openness of management process to a wider range of participants than the traditional actors involved
49 T2.i1: Carrying out (realizations)

T2.i2: Human resources allocated

T2.i3: Process operating framework

T2.i4: Understanding and support

T2.i5: Mission relevance

21 T3.i1: Interest groups involved

T3.i2: Mode of representation

T3.i3: Diversity

T3.i4: Quality

T3.i5: Quantity
Evaluation

$(\%)$

\section{T4: Evolution of public} participation towards approaches more suitable to local contexts and participants
$7 \quad$ T4.i1: Assessment and monitoring

T4.i2: Knowledge, research, and experimentation

T4.i3: Participatory structure

T4.i4: Shared procedural power

$\begin{array}{lll}\%^{\mathbf{a}} & - & + \\ 13 & -73 & 27 \\ 31 & -37 & 63\end{array}$

progressive

T5: Acquisition and exchange of information and knowledge by participants

27 T5.i1: Adaptation, simplicity, and clarity

T5.i2: Science/expertise based and at the vanguard

T5.i3: Relevance, diversity, richness, and completeness

T5.i4: Sharing, integration, and transfer tools

T6: Enhancement of participant's skills

$1 \quad$ T6.i1: Attitude and interpersonal skills T6.i2: Experience and skills for intervention

4) Mobilization of $51 \quad$ T7: Expression of participants participants' motivation/ commitment and enhancement of their capacity to contribute to the management process

$\begin{array}{lllll}51 & \text { T7.i1: Generating and maintaining interest } & 23 & -81 & 19\end{array}$

$\begin{array}{llll}\text { T7.i2: Time and presence } & 19 & -76 & 24\end{array}$

T7.i3: Stability of participants $\quad 5 \quad-\quad-$

$\begin{array}{llll}\text { T7.i4: Involvement and availability of resources } & 16 & -78 & 22\end{array}$

5) Relationships and $\quad 81 \quad$ T8: Changes in attitudes interactions among participants and behaviours with regards to self and to others

T9: Communication
among participants

T10: Development of a collective capacity for collaboration and relationships among participants
35 T8.i1: Trust

T8.i2: Credibility and notoriety

T8.i3: Open mindedness and ways of thinking

T8.i4: Respect and mode of expression

23 T9.i1: Mutual listening

T9.i2: Quality of exchanges

T9.i3: Equity and freedom of expression

65 T10.i1: Knowing and understanding others

T10.i2: Broader networks

T10.i3: Trade-offs and collective interest

T10.i4: Cooperation, team work, and group dynamic 1

T10.i5: Conflict, conciliation, and consensus

$\begin{array}{ccc}15 & -47 & 53 \\ 3 & - & - \\ 20 & -52 & 48 \\ 11 & -75 & 25 \\ & & \\ 4 & - & - \\ 15 & -12 & 88 \\ 7 & - & - \\ & & \\ 19 & -23 & 77 \\ 4 & - & - \\ 35 & -58 & 43 \\ 14 & -31 & 69 \\ 27 & -73 & 27\end{array}$

aPercentage (\%) of respondents that have identified one or more of each impact type or component: $\mathrm{n}=113$.

bercentage (\%) of respondents that have commented on the impact component: $10 \leq n \geq 36$. 
ties, for example. Other challenges mostly concerned conflicts of interest and the way that representatives fulfilled their role (i.e., the way they relate to their respective group).

Little attention was given (7\%) to evolution of public participation practices toward approaches that are more suitable to local contexts and participants $(\mathrm{T} 4)^{10}$, which ranked ninth among respondents' concerns. Although rarely mentioned, this impact is perceived by the great majority as a challenge. Problems related to the creation and maintenance of a structure suitable to the context of application (local traits), or to the delegation of procedural authority to other organizations (when it comes to designing and implementing a public participation process) are discussed. There was only one mention of skills acquisition (T6), which referred to the acquisition of forest management ability and was ranked tenth in importance. Overall, the results showed a great diversity of potential impacts and revealed key achievements and challenges.

\section{Discussion}

The previous section offers a comprehensive picture of the many potential impacts attributed to public participation processes. It also shows how important each is in the concerns of the respondents, as well as the gaps identified between these potential impacts and those that are in fact achieved through participatory processes. This section discusses some of the key theoretical, methodological, and practical considerations related to these findings.

\section{Widening the definition of the impacts of public participation processes}

There are many common points between the impacts identified in our study and the customary concepts used in the literature (See Table 3 for a summary of key terms). Overall, these show that the impacts of public participation processes go well beyond effective impacts to include a range of more subtle ones, primarily reflexive (Moore 1996, Guston 1999, McCool and Guthrie 2001, Beierle and Cayford 2002). This is aptly illustrated by authors such as Halvorsen (2003) or Selin et al. (2000). They observe that key impacts-such as enhanced resource sharing, better communication, change in beliefs about others, and enhanced levels of trust-can happen even though no decisions resulted from the process. Such a broad definition of impacts is relevant in Quebec's forest sector where public participation processes have no formal decision-making power, thereby limiting effective impacts strictly defined as direct power and authority over decisions. This type of definition may help in understanding the reasons explaining why public participation processes continue to be of interest despite their limited power over decisions. Besides, it is worth noting that effective impacts are articulated more subtly in our respondents' view than in standard definitions and typologies (Arnstein 1969). They are conceived as a con-

\footnotetext{
${ }^{10}$ This type of impact is almost absent from the respondents' comments in the interviews, except for rare mentions by "senior" participants who have either witnessed the evolution of the mechanisms or been involved in the implementation of some. These comments were a little more frequent in the questionnaires with coordinators.
}

tinuum including formal power or influence on decisions (T1), increased concrete outcomes and effectiveness of the management process (T2), and involvement of a broader range of participants (T3). Thus, again, limiting effective impacts to a strict definition (i.e., formal decision-making power) ignores important dimensions in the evaluation of the impacts of public participation processes.

When looking at the impact types individually, other parallels can be drawn between our results and the findings of other studies. Together, they highlight interesting trends in relation to the impacts of public participation processes. First, with regard to direct power and influence over decisions (T1), the rather negative assessment of this impact is also observed-few individuals consider that their participation has earned them any real influence over forest management-even though respondents see some of their preoccupations being considered in decisions (Boon and Meilby 2000, Buchy and Race 2001, McCool and Guthrie 2001). In relation to achievement of concrete outcomes and effectiveness of the management process (T2), similarly to our study's results, actions taken on the ground-i.e., concrete products such as preparation and implementation of a plan-are considered to be an important accomplishment of public participation processes, as is the case with the acquisition and exchange of information and knowledge (T5) (Buchy and Race 2001, McCool and Guthrie 2001, Halvorsen 2003, Monnet 2005, McGurk et al. 2006).

In addition, public participation processes are considered to favour the development of participants' skills (T6) (Landre and Knuth 1993). Boon and Meilby (2000) also demonstrate the importance of impacts related to the participants' motivation, commitment, and contribution to the management process (T7). For example, $94 \%$ of their respondents felt that their participation in a public participation process increased their interest in forest management. Furthermore, other studies highlight impacts related to relationships and interactions, particularly with regard to changes in collective capacity (T10), and behaviours and attitudes (T8). The fact of bringing people together and having them interact in a public space, collaborate, listen to and accept each other's perspective, resolve conflicts, and build more solid relationships with one another-which often develop through extended professional networks-are often mentioned as examples of this impact type (Landre and Knuth 1993, Moore 1996, Tuler and Webler 1999, Buchy and Race 2001, Daniels and Walkers 2001, McCool and Guthrie 2001, Halvorsen 2003, McGurk et al. 2006). Finally, the communication (T9) and dialogue among participants that public participation permits is noted (Boon and Meilby 2000, Buchy and Race 2001, McCool and Guthrie 2001). In summary, the findings of other studies tend to confirm our study's findings and, thus, the relevance of considering a wide range of impacts when assessing public participation processes.

\section{Strengthening the evaluation of the impacts of public participa- tion}

The study's results raise methodological and practical challenges for the assessment and measurement of public participation processes' impacts and, overall, for the conception and implementation of participatory processes. 
Direct impact/influence on decisions: management, public policies, normative/strategic, etc. ${ }^{(1,6,7,814,15)} \mathrm{T}$

Consideration of citizen concerns in decisions: decision-making considering all issues/interests ${ }^{(3,10)} \mathrm{T} 1$

Effective decision-making practices: leveraging of resources: money, external expertise guidance/ advice, etc. ${ }^{(3,13,14)} \quad$ T2

Improvement of public policy: more sound and informed collective decisions $(1,4,9,11,14) \quad \mathrm{T} 2$

Identification of priorities and solutions to policy/program issues/problems that are acted upon by policy makers (4) T2

Influence on site-specific operations: plan writing/implementing, forestry practices changes, etc. $(10,11,12,13,14,15) \quad$ T2

Enhancement of sustainability: environment protection, community quality of life, job opportunities, etc. ${ }^{(10,13,16)} \mathrm{T} 2$

Integration of social diversity into discussion/decision-making process: socioeconomic, interests/public values diversity/ representativeness, representation of all, group balance, etc. ${ }^{(1,10,11,12,14,15)}$

Institutionalization of new approaches which get considered or adopted in the arsenal of decision-making tools (6)

Change in vocabularies, agendas, problem statements, public/political debate, etc. (general thinking) ${ }^{(6,7,11)}$

Information sharing and mutual learning (increased awareness/knowledge by individuals: citizens/decision-makers) related to: technical/process-oriented aspects of planning, forest management/issues, etc. ${ }^{(1,2,3,4,5,7,8,9,11,12,13,14,15,16)}$

Data dissemination/diffusion of knowledge (e.g., through dialogue in the support base of representatives) ${ }^{(8,7,14,16)}$

Learning by individuals (empowerment and skills): e.g., capacity for future public involvement $(4,5,9)$

Increase citizen interest in public issues, politics, management (e.g., likelihood to report information seeking) ${ }^{(4,8,9)}$

Collective action and citizenship: more engaged/active citizen more likely to report civic and political involvement/activity (voting, community engagement) ${ }^{(1,4,9)}$

Enabling of social conditions necessary for future processes ${ }^{(17)}$

Changes in beliefs/attitudes: credibility between citizen/decision-makers, legitimacy /support toward decision-making/

officials, trust/confidence in government, public institutions/agencies and among participants $(1,2,3,4,5,9,11,13)$

More public-spirited and tolerant participants (toward those with different viewpoints) ${ }^{(3,4)}$

Individual/collective opinion changes: promote interpretable individual, more sophisticated/internally consistent opinions, and movement toward more moderate policy choices ${ }^{(4,9)}$

Enhancement of the faith in the democratic process ${ }^{(4)}$

Widening and diversification of the participants' networks ${ }^{(4,9)}$

Open communication between actors: constructive dialogue, deliberation, etc. ${ }^{(8,10,12,13,14)}$

Reconciling competing perspectives/interests $=>$ reducing polarization/conflict or litigation over decisions $(1,2,3,9,11,13)$

Increase in the participants' awareness/understanding of views/values different from their own and of the reasons behind these viewpoints/perspectives (mutual learning) $(3,5,9,11,13,14)$

Learning from sponsor organizations on public/stakeholder values, attitudes, and preferred objectives, knowledge, experience, role, organization, contacts, etc. ${ }^{(7,14)}$

Change in interactions between decision makers and citizens and among publics: improved, more personal/long term, working relationships, etc. ${ }^{(3,10,11,12,14,15)}$

Increase in social capital/social bond formation: stronger social ties/sense of community belonging/identity $(4,9,13)$

Increase in the likelihood of cooperation/resource sharing (information, labour, money) ${ }^{(9,13)}$

Development of a collective vision of the public good: shift from self- to common interests and concerns $(3,4,9,10)$

${ }^{a}$ For the detailed version see Martineau-Delisle [In prep.].

${ }^{(1)}$ Beierle and Cayford 2002; ${ }^{(2)}$ Côté and Bouthillier 2002; ${ }^{(3)}$ Halvorsen 2003; ${ }^{(4)}$ Abelson and Gauvin 2006; ${ }^{(5)}$ Landre and Knuth 1993; ${ }^{(6)}$ Einsiedel et al. 2001; ${ }^{(7)}$ Guston 1999;

${ }^{(8)}$ Boon and Meilby 2000; ${ }^{(9)}$ Delli Carpini et al. 2004; ${ }^{(10)}$ Moore 1996; ${ }^{(11)}$ Konisky et Beierle 2001; ${ }^{(12)}$ McCool and Guthrie 2001; ${ }^{(13)}$ Selin et al. 2000; ${ }^{(14)}$ Beckley et al. 2005;

${ }^{(15)}$ McGurk et al. 2006; ${ }^{(16)}$ Duram et Brown 1999; ${ }^{(17)}$ Webler et al. 2001.

Influence of the type of participatory technique on the types of impacts that occur

The study's findings suggest the participatory technique used has an influence on the types of impacts that occur and, thus, on their assessment by the individuals involved. For example, respondents noted the important contribution made by committees to communication among participants and to relationship building. Other considerations, such as the number of participants, had little place in their concerns. Less deliberative techniques (e.g., public hearings), which were excluded from the initial sample of cases, show different trends. For example, quantity of participants is treated as a significant dimension in the respondents' comments, contrary to types of impacts related to relationship building that are of minor importance in their discourse (Martineau-Delisle [In prep.]). These observations suggest that some techniques may be bet- 
ter suited to achieve certain types of impacts. Furthermore, they underscore the importance of targeting the right evaluation dimensions when assessing the impacts of a public participation process.

\section{Influence of other public participation process' traits on impacts}

In addition to the participatory technique, the respondents' concerns indicate parallels that can be drawn with other descriptive variables associated with public participation processes. First, as noted previously, forest-related committees, which act mainly as advisors, have little or no decisionmaking power (Boon and Meilby 2000). At the present time in Quebec, according to a strict definition of decision-making power, the public participation mechanisms that provide for formal decision-making authority are rare (MartineauDelisle [In prep.]). This translates into a rather negative assessment by our respondents of their power over decisions and their capacity to act, an observation that is supported by other studies (Boon and Meilby 2000, Buchy and Race 2001, McCool and Guthrie 2001). In that regard, McGurk et al. (2006) underline the difference between influence on "operational, site-specific decisions: placement of roads, buffers, bridges, and cut blocks"- on which committee members recognized that they had on some occasions had an impactand influence over normative and strategic decisions, the latter being considered a key weakness.

As is the case with impacts related to influence over normative and strategic decisions, impacts related to participant mobilization are among those that are considered to present key challenges. This observation reveals another example of the link between attributes related to public participation processes and impacts. Indeed, a majority of the committees in our study allocate no resources to support the participation of participants (62\%). Those that do provide for travel expenses $(28 \%)$, meals (13\%), per diems (11\%) or others items (e.g., room, child care expenses, accommodation, parking) $(12 \%)$, offer a level of support that appears to be lower than is offered elsewhere in Canada (Parkins et al. 2006). In addition, many participants are volunteers and not all participating organizations have the same resources to invest in this effort. Overall, these observations illustrate that expected impacts need to be clearly identified right from the design phase of a public participation process. The key process traits will increase the likelihood of impact achievement must also be carefully examined.

\section{Some key considerations for the assessment and measure- ment of impacts}

Finally, the study reveals that public participation's impacts are more diverse, but also that they manifest themselves in a more complex manner than is generally conceived. A key issue relates to the connections between impacts, i.e., how a specific impact can be instrumental in achieving another. For example, as illustrated by McGurk et al. (2006):

"[A] key outcome strength was developing trust and building new relationships, which was spurred by the information sharing and communicative learning. [...] Relationship-building permitted committee members to work together to, among other things, influence sitespecific decisions that companies had to make about their harvesting plans" (pp. 821-822).
Another factor to consider relates to time influence. Moore (1996) noted in that regard:

"Success may be sequential, with one success building on another...getting a written agreement may depend on engendering political support for the process and establishing relationships-and participants" perceptions regarding the relative importance of different categories of success may change over time" (p. 167).

\section{Conclusion}

Although the evaluation of public participation processes is still a marginal concern at the practitioner's level, there are major trends indicating that this might be about to change. In Canada, the criteria-and-indicators frameworks adopted by the federal and provincial governments - and by certification standards bodies - to monitor forest management sustainability all involve the measurement of public participation results (CCFM 1995, 2003; Bureau du forestier en chef 2010). As the indicators have been evolving rapidly in recent years, it is likely that they will be refined to the point of incorporating an evaluation of public participation processes that is more systematic and that goes beyond simple participant satisfaction (i.e., including an assessment of impacts). Consequently, there are major methodological and practical challenges that need to be dealt with in relation to the empirical measurement of the impacts of public participation (Rowe et al. 2005). In undertaking this study, not only did we seek a deeper understanding of the impacts of participatory processes but we also aimed to contribute with practical knowledge to help overcome some of these challenges.

Based on an approach where the views of participants are seen as central to the assessment of public participatory processes, the study refines and expands the definition of the "impacts of public participation" by providing a framework comprising ten impact types and defining dimensions. Hence, from a practical point of view, the study provides a reference point for the evaluation of the impacts of public participation mechanisms (e.g., the types of impacts or dimensions that may be evaluated and reported on). Thus, the framework could inspire the development of tools for assessing the impacts of participatory processes-a logic model for performance measurement or an evaluation grid for processes designed to be suitable for a wide variety of techniques, for example (Halvorsen 2001).

The study's results show that the benefits of public participation practices are reflected in a variety of impacts, among which the effective impacts are important but do not dominate the participants' concerns. The study also demonstrates that respondents' assessment of the capacity of mechanisms to have the expected benefits differs from one impact to another. Although many factors may have an influence on their evaluation, one is of particular interest: the high-level vision of public participation. For example, contrary to a democratic vision that values the openness of the decisionmaking process to a diversity of participants (Fiorino 1990), an instrumental vision gives more importance to impacts related to concrete outcomes and to the effectiveness of the management process. This suggests caution with respect to evaluation of impacts and development of success criteria for public participation processes. Since there are no universal benchmarks for assessing impacts, the high-level goals 
against which a participatory process is evaluated (i.e., the specific high-level vision of public participation) must be clearly specified; a wide range of impact types should also be assessed (Buchy and Race 2001, McCool and Guthrie 2001, Smith Korfmacher 2001).

The study raises many questions and avenues for future research and practices that could help both in gaining a deeper understanding of the impacts of public participation and in supporting the implementation of the lessons learned. First, to validate or complete the picture of potential impacts, it would be relevant to do a similar analysis with a larger sample of respondents, but also to assess the influence that participants' affiliations and roles might have on their assessment of the impacts of public participation (e.g., industrial, environment, coordinator, participant in the strict sense, expert). Furthermore, the analysis should be extended to all existing public participation techniques-committees, public hearings, online consultations, etc. Other research avenues include the connections between impacts-how a specific impact type can be instrumental in achieving another impact - as well as the study of public participation cases over time to see how the achievement of impacts is transformed and what influence it has on the participants' evaluation (Moore 1996, Selin et al. 2000).

From another point of view, given that the study's results highlight strengths and weaknesses of current committees as well as key issues associated with participants' satisfaction, they may inspire the design and implementation of future public participation initiatives. In particular, practitioners should recognize the enlargement of the definition of the impacts of public participation processes as having important implications for processes design. For example, as suggested by McGurk et al. (2006):

"... the communicative potential of such models should be emphasized when establishing committee mandates, setting goals and objectives, creating procedures and protocols, and allocating budgets and human resources. Emphasizing information flows, communication, deliberation, and learning can greatly increase the likelihood of building stakeholder capacity and realizing the full potential of the SAC [Stakeholder Advisory Committee] model." (p. 824)

Moreover, although our study observed gaps between the participants' vision and existing participatory practices, it provides directions on areas where efforts may be invested to ensure that some impacts happen in reality (Beierle and Cayford 2002). In particular, it could help in identifying priority areas for improvement for some of the gaps that have been identified recently with regard to public participation in forest management in Quebec (Bureau du forestier en chef 2010).

To conclude, the study leads to key practical lessons related to the impacts of public participation processes that are of relevance to public participation practitioners (MartineauDelisle [In prep.]). Table 4 provides examples of recommendations that flow from the lessons learned through the study.

Finally, it must be noted that impact assessment is central to the emerging approaches characterizing forest management- "ecosystemic", "adaptive", "sustainable forest" management and so forth (Selin et al. 2000, Stringer et al. 2006). Such assessment is expected to contribute to a continuous feedback loop and learning process, which are key elements of the new forest regime and forestry legislation enacted by
Table 4: Key practical lessons related to the impacts of public participation process

- The assessment tools for evaluating the impacts of public participation processes should allow for an adequate measurement of individuals' perceptions.

- The assessment of the impacts of public participation should cover a broad range of impact types.

- The performance indicators used in the evaluation of impacts should be targeted to the participatory technique evaluated (e.g., deliberative versus other forms of techniques).

- The choice of techniques and identification of public participation process traits are to be determined based on the impact types targeted.

- Sufficient time should be dedicated to the development of a framework to clearly distinguish process traits and desired impacts when conceiving and evaluating a process.

Quebec in 2010. Overall, impact assessment is a key dimension of our capacity to report on progress towards sustainable forest governance, including meaningful and effective public participation.

\section{Acknowledgements}

The authors greatly appreciate the constructive suggestions made by reviewers of this paper and their assistance in its improvement. The authors would also like to thank the many people who provided invaluable information and insights, especially public participation managers, practitioners, and participants who collaborated with the researcher in the course of the study. Finally, the authors are grateful for the financial support of the following organizations: Social Sciences and Humanities Research Council, Sustainable Forest Management Network, Fonds québécois pour la recherche sociale (FQRS), Natural Resources Canada (Canadian Forest Service), Fondation Desjardins, and Commission Coulombe (Ministère des Ressources naturelles et de la faune du Québec).

\section{References}

Abelson, J., P.-G. Forest, J. Eyles, A. Casebeer and G. Mackean. 2004. Will It Make a Difference if I Show Up and Share? Citizen Perspectives on Improving Public Involvement in Health System Decision-Making. Journal of Health Services Research and Policy 9 (4): 205-212.

Abelson, J. and F.-P. Gauvin. 2006. Assessing the Impacts of Public Participation: Concepts, Evidence, and Policy Implications. Canadian Policy Research Networks. Ottawa.

Arnstein, S.R. 1969. A Ladder of Citizen Participation. American Institute of Planners Journal 35: 216-224.

Beckley, T., J. Parkins and S. Sheppard. 2005. Public Participation in Sustainable Forest Management: A Reference Guide. Sustainable Forest Management Network. Edmonton, AB.

Beierle, T.C. and J. Cayford. 2002. Democracy in Practice. Public Participation in Environmental Decisions. Resources for the Future. Washington, DC.

Boon, T.E. and H. Meilby. 2000. Enhancing Public Participation in State Forest Management: A User Council Survey. Forestry 732: 155-64.

Buchy, M. and D. Race. 2001. The Twists and Turns of Community Participation in Natural Resource Management in Australia: What is Missing? Journal of Environmental Planning and Management 44 (3): 293-308. 
Bureau du forestier en chef. 2010. Bilan d’aménagement forestier durable au Québec 2000-2008. Gouvernement du Québec. Roberval, QC.

[CCMF] Canadian Council of Forest Ministers. 1995. Defining Sustainable Forest Management: A Canadian Approach to Criteria and Indicators. Available at http://www.ccfm.org/ci/defining 1997_e.html

. 2003. Defining Sustainable Forest Management: Criteria and Indicators 2003. Ottawa.

[CSA] Canadian Standards Association. 2008. Sustainable Forest Management. Mississauga, Ontario. Available on line: http://www. csagroup.org/\%5Crepository\%5Cgroup\%5CZ809-08.pdf.

Cashore, B., G. Cornelis Van Kooten, I. Vertinski, G. Auld and J. Affolderbach. 2005. Private or Self-Regulation? A Comparative Study of Forest Certification Choices in Canada, the United States and Germany. Forest Policy and Economics 7 (1): 53-69.

Cortner, H.J. and M.A. Moote. 1999. The Politics of Ecosystem Management. Island Press, Washington, DC.

Côté, M.A. and L. Bouthillier. 2002. Assessing the Effect of Public Involvement Processes in Forest Management in Quebec. Forest Policy and Economics 4: 213-25.

Daniels, S.E. and G.B. Walker. 2001. Working through Environmental Conflict: The Collaborative Learning Approach. Praeger Publisher, Westport, CT.

Delli Carpini M.X., F. Lomax Cook and L. Jacobs. 2004. Public Deliberation, Discursive Participation, and Citizen Engagement: A Review of the Empirical Literature. Annual Review of Political Science 7 (1): 315-344.

Diduck, A. and J.A. Sinclair. 2002. Public Involvement in Environmental Assessment: The Case of the Nonparticipant. Environmental Management 29(4): 578-588.

Dorcey, A.H.J. and T. McDaniels. 2001. Great Expectations, Mixed Results: Trends in Citizen Involvement in Canadian Environmental Governance. In E.A. Parson (ed.). Governing the Environment. University of Toronto Press. Toronto, ON.

Dubé R.A., C. Chabot, B. Lortie and R. Pomerleau. 2004. Bilan sommaire des consultations publiques des dernières années. Rapport préparé pour la Commission d'étude sur la gestion de la forêt publique québécoise. Québec, QC.

Duram, L.A. and K.G. Brown. 1999. Assessing Public Participation in U.S. Watershed Planning Initiatives. Society \& Natural Resources 12(5): 455-67.

Einsiedel, E., E. Jelsoe and T. Breck . 2001. Publics at the Technology Table: The Consensus Conference in Denmark, Canada, and Australia. Public Understanding of Science 10: 83-98.

Fiorino, D.J. 1990. Citizen Participation and Environmental Risk: A Survey of Institutional Mechanisms. Science, Technology, \& Human Values. 152: 226-243.

[FSC] Forest Stewardship Council Social Strategy Advisory Committee. 2003. FSC Social Strategy: Building and Implementing a Social Agenda Version 2.1. Available at http://www.fsc.org/keepout/ en/content_areas/77/32/files/FSC_Social_Strategy_version_2_1.pdf Gaudin, J.-P. 1998. La gouvernance moderne, hier et aujourd'hui : Quelques éclairages à partir des politiques publiques françaises Revue internationale des sciences sociales 155: 51-60.

Germain, R.H., F.W. Floyd and S.V. Stehman. 2001. Public Perception of the USDA Forest Service Public Participation Process. Forest Policy and Economics 3: 113-24.

Guston, D.H. 1999. Evaluating the First U.S. Consensus Conference: The Impact of the Citizens' Panel on Telecommunications and the Future of Democracy. Science, Technology, \& Human Values 244: 451-82.

Halvorsen, K.E. 2001. Assessing Public Participation Techniques for Comfort, Convenience, Satisfaction, and Deliberation. Environmental Management 282: 179-86.

Halvorsen, K.E. 2003. Assessing the Effects of Public Participation. Public Administration Review 63(5): 535-543.
Halvorsen, K.E. 2006. Critical Next Steps in Research on Public Meetings and Environmental Decision Making. Human Ecology Review 12(2): 150-160.

Hamel, P. 2003. Enjeux institutionnels et défis politique. In J.G. Vaillancourt and K. Gendron (dirs.). Développement durable et participation publique : de la contestation écologiste aux défis de la gouvernance. Les Presses de l'Université de Montréal, Montréal, QC.

Howlett, M. (ed.). 2001. Canadian Forest Policy: Adapting to Change. University of Toronto Press, Toronto, ON.

Hunt, L. and W. Haider. 2001. Fair and Effective Decision Making in Forest Management Planning. Society \& Natural Resources 14: 873-87.

Irvin, R.A. and J. Stansbury. 2004. Citizen Participation in Decision Making: Is It Worth the Effort? Public Administration Review 64 (1): 55-65.

Johnson, B.R. and R. Campbell. 1999. Ecology and Participation in Landscape Planning Within the Pacific Northwest. Policy Studies Journal 27 (3): 502-529.

Konisky, D. and T.C. Beierle. 2001. Innovations in Public Participation and Environmental Decision Making: Examples from the Great Lakes Region. Society \& Natural Resources 149: 815-26.

Lafaye, C. 2001. Gouvernance et démocratie: quelles configurations? In L. Cardinal and C. Andrew (dirs.). La démocratie à l'épreuve de la gouvernance, Presses de l'Université d'Ottawa. Ottawa.

Landre, B.K. and B.A. Knuth. 1993. Success of Citizen Advisory Committees in Consensus-Based Water Resources Planning in the Great Lakes Basin. Society \& Natural Resources 6: 229-57.

Lauber, B.T. and B.A. Knuth. 1999. Measuring Fairness in Citizen Participation: A Case Study of Moose Management. Society \& Natural Resources 11: 19-37.

Lecomte, N., C. Martineau-Delisle and S. Nadeau. 2005. Participatory requirements in forest management planning in Eastern Canada: A temporal and interprovincial perspective. The Forestry Chronicle 81(3): 398-402.

Lequin, M. 2001. Écotourisme et gouvernance participative. Presses de l'Université du Québec. Québec, QC.

Martineau-Delisle, C. [In prep.]. Un changement de gouvernance en forêt? La participation publique à la gestion forestière québécoise : évolution, impacts et participants. Thèse de doctorat. Faculté des sciences sociales, Université Laval, Québec, QC.

McCool, S. and K. Guthrie. 2001. Mapping the Dimensions of Successful Public Participation in Messy Natural Resources Management Situations. Society \& Natural Resources 144: 309-23.

McGurk, B., J. Sinclair and A. Diduck. 2006. An Assessment of Stakeholder Advisory Committees in Forest Management: Case Studies from Manitoba, Canada. Society \& Natural Resources 19(9): 809-826.

Miles, M.B. and A.M. Huberman. 1994. Qualitative Data Analysis: A Sourcebook of Methods. Sage Publications, Beverly Hill, CA.

Monnet, S. 2005. L'apprentissage collaboratif, outil d'évaluation de la décision en aménagement forestier. Létude du cas de la Table de concertation Av 043-20. Thèse de doctorat. Faculté de foresterie et de géomatique, Université Laval, Québec, QC.

Moore, S.A. 1996. Defining "Successful" Environmental Dispute Resolution: Case Studies from Public Land Planning in the United States and Australia. Environmental Impact Assessment Review 16(3): 151-169.

[OECD] Organisation for Economic Cooperation and Development. 2001. Citizens as Partners: Information, Consultation, and Public Participation in Policy-Making. Available at http://www. oecdbookshop.org/oecd/display.asp?K=5LMQCR2KHGS8\&DS= Citizens-as-Partners

Parkins, J., S. Nadeau, L. Hunt, J. Sinclair, M. Reed and S. Wallace. 2006. Public Participation in Forest Management: Results from a National Survey of Advisory Committees. Northern Forestry Centre, Canadian Forest Service, Edmonton, AB. Information Report NOR-X-409. 
Robinson, D., M. Robson and R. Rollins. 2001. Towards Increased Citizen Influence in Canadian Forest Management. Environments 29(2): 21-41.

Rowe, G. and L.J. Frewer. 2004. Evaluating Public-Participation Exercises: A Research Agenda. Science, Technology, \& Human Values 29(4): 512-556.

Rowe, G., T. Horlick-Jones, J. Walls and N. Pidgeon. 2005. Difficulties in Evaluating Public Engagement Initiatives: Reflections on an Evaluation of the UK GM Nation? Public Debate about Transgenic Crops. Public Understanding of Science 14(4): 331-352.

Selin, S. W., M.A. Schuett and D. Carr. 2000. Modeling Stakeholder Perceptions of Collaborative Initiative Effectiveness. Society \& Natural Resources 13(8): 735-745.

Smith Korfmacher, K. 2001. The Politics of Participation in Watershed Modeling. Environmental Management 27(2): 161-176.

Smouts, M-C. 1998. Du bon usage de la gouvernance en relations Internationales. Revue internationale des sciences sociales 155: 85-94.

Stankey, G.H., R.N. Clark and B.T. Bormann. 2005. Adaptive Management of Natural Resources: Theory, Concepts, and Management Institutions. U.S. Department of Agriculture, Forest Service, Pacific Northwest Research Station, Portland, OR. Gen. Tech. Rep. PNW-GTR-654.
Stoker, G. 1998. Cinq propositions pour une théorie de la gouvernance. Revue internationale des sciences sociales 155: 19-30.

Strauss, A.L. and J.M. Corbin. 1990. Basics of Qualitative Research: Grounded Theory Procedures and Techniques. Sage Publications, Newbury Park, CA.

Stringer, L. C., A. J. Dougill, E. Fraser, K. Hubacek, C. Prell and M. S. Reed. 2006. Unpacking "Participation" in the Adaptive Management of Social-Ecological Systems: A Critical Review. Ecology and Society 11(2): 39 .

Tuler, S. and T. Webler. 1999. Voices from the Forest: What Participants Expect of a Public Participation Process. Society \& Natural Resources 12(5): 437-453.

Webler, T. and S. Tuler. 2000. Fairness and Competence in Citizen Participation: Reflections from a Case Study. Administration and Society 32(5): 56-95.

Webler, T., S. Tuler and K. Rob. 2001. What Is a Good Public Participation Process? Five Perspectives from the Public. Environmental Management 27(3): 435-450. 